\title{
Cerebral Venous Sinus Thrombosis Associated with Spontaneous Intermittent Cerebrospinal Fluid Rhinorrhea: A Case Report
}

\author{
Uygar Utku $^{a}$ Mustafa Gokce ${ }^{a}$ Mehmet Senoglu ${ }^{b}$ \\ Departments of a Neurology and ${ }^{b}$ Neurosurgery, Faculty of Medicine, Kahramanmaras Sutcu Imam University, \\ Kahramanmaras, Turkey
}

\section{Key Words}

Spontaneous intermittent cerebrospinal fluid rhinorrhea Cerebral venous sinus thrombosis $\cdot$ Skull base defect

\begin{abstract}
Objectives: To present a rare case of cerebral venous sinus thrombosis (CVST). Clinical Presentation and Intervention: A 43-year-old woman presented with coma and was diagnosed as a case of CVST. She recovered in a few days with heparin treatment. Many possible risk factors for CSVT were negative in the patient but intermittent cerebrospinal fluid (CSF) rhinorrhea was accidentally noticed. Cerebral computed tomography and magnetic resonance imaging were done. The patient was diagnosed as having spontaneous intermittent CSF rhinorrhea due to a defect in the base of the skull. Conclusions: This case showed the importance of being aware that a defect in the base of the skull may lead to intermittent CSF rhinorrhea in patients with CVST.
\end{abstract}

Copyright $\odot 2012$ S. Karger AG, Basel

\section{Introduction}

Cerebral venous sinus thrombosis (CVST) causes obstruction of both major veins and sinuses within the cerebrum $[1,2]$. The diagnosis of CVST is still commonly overlooked or delayed because of the remarkable diversity of its clinical symptoms, modes of onset, and neuroimaging signs $[1,2]$. Hypercoagulability has been found in approximately $85 \%$ of patients with CVST while no risk factor has been found in the remaining 15\% [1]. The cerebrospinal fluid (CSF) leak may be a cause for CVST. Spontaneous, traumatic or post-lumbar puncture CSF leak is sometimes but not frequently associated with CVST presentation [3-7]. We were not able to find a report of spontaneous intermittent CSF leak due to a defect in the base of the skull associated with CVST in the English literature. Here, we report on a patient with CVST associated with spontaneous intermittent CSF rhinorrhea due to a defect in the base of the skull.

\section{Case Report}

A 43-year-old woman was hospitalized with complaints of headache, fever and increased levels of blood glucose at a neurology clinic of a state hospital in Kahramanmaras. Antibiotic, antihypertensive, and insulin treatment were given to the patient, but the patient's condition became worse during the 3 days of hospitalization; hence, she was referred to our hospital.

In the Department of Emergency, she did not open her eyes to painful stimulation, but was groaning and on neurological examination, slight movement of her extremities was detected. There was no neck stiffness. Her funduscopic and remaining neurologic examinations were unremarkable. Her past history was

\section{KARGER}

Fax +4161306 1234

E-Mail karger@karger.ch

www.karger.com
(C) 2012 S. Karger AG, Basel

1011-7571/12/0214-0392\$38.00/0

Accessible online at:

www.karger.com/mpp
Dr. Uygar Utku

Department of Neurology, Faculty of Medicine

Kahramanmaras Sutcu Imam University

TR-46050 Kahramanmaras (Turkey)

Tel. +90 3442212337 ext. 141, E-Mail utkuzar@gmail.com 
Fig. 1. CT venography of the patient's head shows thrombosis in the sinuses (arrows). Fig. 2. a Noncontrast CT shows skull base defect at the posterior wall of the left sphenoid sinus (arrow). b Skull base defect at the left sphenoid sinus posterior wall is seen in the bone window of the multidetector paranasal CT. c Head MRI showing air-fluid level in the left sphenoid sinus seen on $\mathrm{T}_{2}$-weighted images.
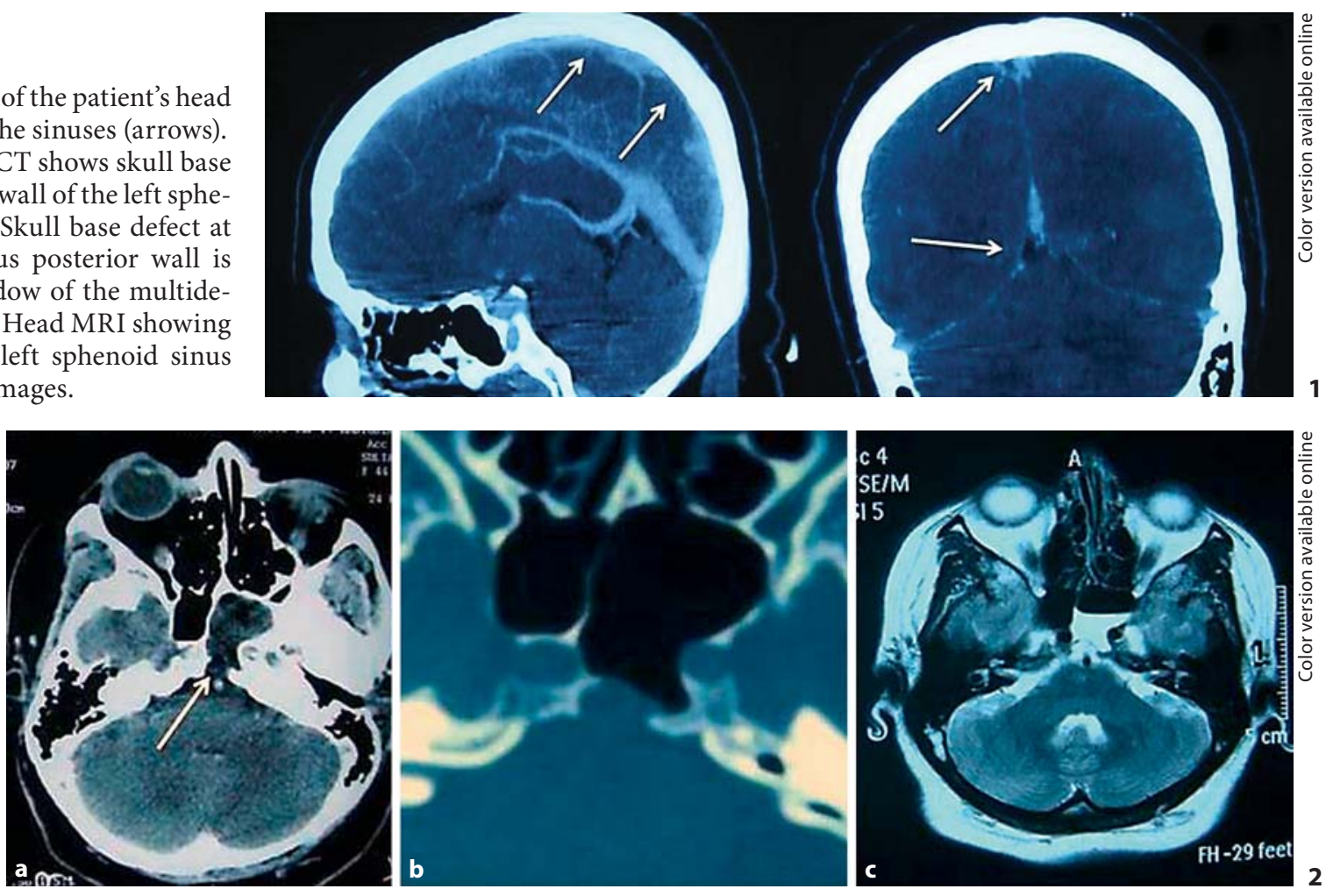

positive for suspected hyperglycemia. She denied any cranial trauma. Routine biochemistry and hemogram were unremarkable. No sign of lumbar puncture was observed. Her brain CT venography revealed partial thrombosis at the sinuses (fig. 1). The patient was given a full dose of heparin anticoagulant and she almost completely recovered within 5 days. Protein S, protein C, factor $\mathrm{V}$ Leiden mutation, antithrombin III and prothrombin G20210A mutation were all negative. A discharge from her left nostril was incidentally noticed. When she was queried about the rhinorrhea, we learned that she had had intermittent rhinorrhea on her left nostril for many years of her life. A paranasal sinus CT and cranial magnetic resonance imaging (MRI) revealed a defect at the base of the skull at the left sphenoid sinus posterior wall on paranasal sinus CT and cranial MRI (fig. 2). Surgery was postponed because the rhinorrhea stopped spontaneously. She has now been taking warfarin for more than 1 year and there has been no other problem.

\section{Discussion}

CVST has several etiologies that include lumbar puncture on spinal anesthesia but our case had spontaneous intermittent CSF leak due to a defect in the base of the skull $[3,4]$. A proposed mechanism of this condition is that a low CSF pressure causes a downward shift of the brain with increased pressure on the cerebral veins and sinuses. The increased pressure compresses the venous walls, thereby increasing the risk of thrombosis. Use of myelography or epidural injection has confirmed this theoretical possibility [3]. Hypercoagulability risk factors such as protein $\mathrm{S}$, protein $\mathrm{C}$, factor $\mathrm{V}$ Leiden mutation, antithrombin III and prothrombin G20210A mutation were all negative in our case. She was neither pregnant nor puerperal nor on contraceptive pills, and she did not have any past or family history of venous thrombosis. Hence, we speculate that CVST probably occurred due to intracranial hypotension resulting from intermittent CSF rhinorrhea. Whatever the cause for CVST, anticoagulation has been suggested for its treatment even when it is associated with cerebral hemorrhage [8]. Our patient was on heparin for a few days.

Defects at the base of the skull leading to spontaneous CSF rhinorrhea are rare lesions accounting for only 3-5\% $[9,10]$. The term 'spontaneous CSF rhinorrhea' has been applied to describe nasal discharge of CSF unrelated to trauma, surgery, malformation, tumor, or previous radiation therapy. However, our patient did not have a history of trauma, surgery or radiation therapy. CSF leak occurs at the base of the skull with direct communication of the 
subarachnoid space to the extracranial space, usually a paranasal sinus. CSF leak describes the passage of CSF from the intracranial cavity through an osseous defect within the base of the skull that could be detected on CT and cranial MRI scans, as happened in our patient.

With the advent of modern thin-section and multidetector CT scanners, smaller defects can be visualized with a reported sensitivity as high as $92 \%$ and specificity of $100 \%[9,10]$. Axial images are considered best for evaluation of the posterior wall of the frontal sinus, posterior and lateral walls of the sphenoid sinus, and the mastoid complex $[9,10]$. Axial images of multidetector paranasal sinus CT were used to confirm the defect of the base of the skull for our patient. Actually, in our patient's skull, the base defect was easily seen on her brain CT. Therefore, the spontaneous intermittent CSF rhinorrhea was due to the defect at the base of the skull.

\section{Conclusion}

This was a case of CVST due to spontaneous intermittent CSF rhinorrhea associated with skull base defect. The case highlights the importance of paying attention to the base of the skull in cases of spontaneous intermittent CSF rhinorrhea as a risk factor for CVST.

\section{References}

1 Bousser MG, Ferro JM: Cerebral venous thrombosis: an update. Lancet Neurol 2007; 6:162-170.

2 Stam J: Thrombosis of cerebral veins and sinuses. N Engl J Med 2005;352:1791-1798.

3 Mehdiratta M, Kumar S, Selim M, Caplan LR: Cerebral venous sinus thrombosis; in Caplan LR (ed): Uncommon Causes of Stroke, ed 2. New York, Cambridge University Press, 2008, pp 497-504.

4 De Frietas GR, Bogousslavsky J: Risk factors of cerebral vein and sinus thrombosis; in Caso V, Agnelli G, Paciaroni M (eds): Handbook of Cerebral Venous Thrombosis. Basel, Karger, 2008, pp 23-55.
5 Berroir S, Grabli D, Heran F, Bakouche P, Bousser MG: Cerebral venous thrombosis in two patients with spontaneous intracranial hypotension. Cerebrovasc Dis 2004;17:9-12.

6 Ivanidzea J, Zimmerman RD, Sanelli PC: Spontaneous intracranial hypotension followed by dural sinus thrombosis: a case report. Clin Neurol Neurosurg 2010;112:498500.

7 Schievink WI, Maya MM: Cerebral venous thrombosis in spontaneous intracranial hypotension. Headache 2008;48:1511-1519.
8 Hegazi MO, Ahmed S, Sakr MG, Hassanien OA: Anticoagulation for cerebral venous thrombosis with subarachnoid hemorrhage: a case report. Med Princ Pract 2010;19:7375.

$\checkmark 9$ Lloyd KM, DelGaudio JM, Hudgins PA: Imaging of skull base cerebrospinal fluid leaks in adults. Radiology 2008;248:725-736.

10 Laine FJ, Nadel L, Braun IF: CT and MR imaging of the central skull base. Part I: techniques, embryologic development, and anatomy. Radiographics 1990;10:591-602. 